\title{
Climate Change and Development: A Tale of Two Crises
}

Peter Newell*

\section{Introduction}

The starting point for this Bulletin is both a recognition of the lack of attention to climate change within contemporary donor discourse and a growing frustration with the untenability of such a position; ignoring a problem that is so deeply implicated in prevailing models of development. The fact that climate change has been so neglected as an issue by the mainstream development community should not come as a surprise, however. Not only because, despite the rhetoric, most environmental issues have yet to be effectively mainstreamed within development policy and practice, but because climate change raises a series of uncomfortable challenges for the theory and practice of development.

To the extent that climate change highlights the unsustainability of the fossil-fuelled growth trajectory that underpins the contemporary global economy, it focuses scrutiny on the economic growth strategies promoted by the world's leading global economic institutions, most notably, the World Bank and the International Monetary Fund (IMF). Because of the enormous global climate footprint that results from the increased movement of goods transported around the world as a result of lower trade barriers, the World Trade Organisation (WTO) and the governments that created it and use it to their advantage, necessarily also enter the spotlight.

Despite criticism from some quarters that climate change assumes too high a status on the global agenda, it is widely recognised as one of the most serious threats currently facing humankind and its poorest members in particular. Indeed, a 2003 multi-donor report on Poverty and Climate Change rightly acknowledges that "Climate change is a serious risk to poverty reduction and threatens to undo decades of development efforts' (Sperling 2003: 5). The relative lack of action to date has less to do with the painfully slow diplomatic processes required to secure global agreement on solutions to the problem than to the vested interests, governments included, that benefit, in the short term at least, from doing nothing. Unfortunately, it is these same governmental and corporate actors that wield such influence within the institutions with the power to chart a climate benign development path, but for the same reasons find it easier to promote fossil-fuel-led development trajectories across the developing world.

Within the development community, climate change has been interpreted within conventional frames of analysis. It is a problem of bad governance and inefficient markets. To cite the report mentioned above; "By making public institutions responsive, participative and accountable to those they serve, decision making process and implementation activities can be robust enough to deal with the challenge of climate change' (p. 24). It abounds with "win-win" opportunities and the potential for synergy and, of course, action is more likely to be effective if it is "demand-driven", responding to the needs of the poor. The purpose here is not to pour scorn on these development mantras, as many, in practice at least, contain valuable insights into the political and institutional dimensions of the climate change problem. Rather, it is to show that by not thinking beyond these convenient frames of interpretation, we miss an important opportunity to effect more substantive change in preventing climate change from further immizerising the lives of the poor by critically revisiting the role of conventional development strategies in producing the problem in the first place. I develop this argument by looking at the importance of policy 
coherence in relation to the policies and, by implication, ecological footprint, of the bilateral and multilateral development institutions, the private sector and finally turn to the potential and limitations of the contemporary popularity among donors of climate adaptation strategies.

\section{The challenge of policy integration}

Policy integration is perhaps the greatest contribution that governments can make towards providing climate protection and it is also potentially the least economically costly. By ensuring that policies in areas such as energy, agriculture, transport and industry are designed with the imperative of climate protection in mind, governments will be going along way towards addressing the problem of climate change in a way that helps to avoid the need for expensive mitigation and adaptation projects at a later stage. The goal of policy integration has been clearly articulated, even if not fully practiced, by the European Union (EU) and there are lessons from this experience, which could guide other governments responses to climate change (Grant, Matthews and Newell 2000).

What this means is not viewing climate change as an isolated problem, but rather as a product of a whole series of policy choices about economic and energy strategy that need to be revised to ensure minimal impact on climate change. Otherwise the effects of actions taken to protect the climate will continue to be systematically offset by decisions taken in policy areas such as energy, trade, transport and agriculture. At the moment, governments' professed commitments to tackle climate change, expressed in the Kyoto Protocol, are being systematically undermined by their continued support for financial institutions that promote activities that generate vast amounts of greenhouse gases. As Tellam puts it:

While the governments of industrialised countries continue to publicly state their commitment to dealing with the climate issue under the Kyoto Protocol, they continue to work with the World Bank, with multilateral development banks and with export credit agencies to directly or indirectly finance the development of energy systems in low-income countries based on fossil-fuels. (Tellam 2000: 185)
Until now, climate change has rightly been viewed as a rich country problem. It has been largely created by the fossil fuel intensive patterns of industrialisation from which we have benefited in Europe, North America and East Asia. The problem is that the impacts of climate change will be, many argue already are, being felt most acutely by the world's poorest nations. In addition, the rapid industrialisation of parts of South-East Asia, China and South America has created a situation in which the former North/South dynamic has given way to a recognition that many of countries within these regions will join the ranks of the largest polluters within the next two decades. Whereas development practitioners are used to working with the poor, with climate change we have to recognise that to avert further displacement and suffering as a result of climate change, we need to identify and enforce a new set of policy mechanisms in the industrialised and new industrialising world for integrating climate change objectives within policy areas that have traditionally been perceived to have nothing to do with either development or environment. This requires us to look not only at the activities of governments, but at the international institutions and market actors that shape so strongly the direction of national development strategies.

\section{The role of bilaterals and multilaterals}

Above and beyond other development actors, the World Bank has the potential to finance a number of important climate protection initiatives, as well as reduce the climate-changing impact of existing development strategies. In addition to being an implementing agency of the Global Environment Facility (GEF), the financing agency for the climate agreements, the Bank has a separate Climate Change Programme made up of three components: Climate Change Overlays Programme; World Bank Activities Implemented Jointly (AIJ) programme and the Global Carbon Initiative. The Bank also has a Clean Coal Initiative intended to encourage the use of "environmentally friendly" coal technologies. Helping to promote the exchange of information, the Bank also runs 'EMPower Info', a focal point for information about environmental assessment processes, the environmental impacts of different energy sources and about pollution mitigation technologies. The Bank is also playing a part in advancing the goals of the global climate regime by 
launching a Prototype Carbon Fund, with investments from private sector firms, intended to facilitate acquisitions and transfers of credits from the flexible mechanisms created by the Kyoto Protocol.

There are a number of barriers to the World Bank making a greater contribution to the financing of climate action, however. One of the most serious, is the failure of effective policy integration; the lack of systematic integration of the goals of climate change protection into mainstream lending activities. According to Tellam 'progressive initiatives are very small compared to the Bank's overall portfolio' and are generally dependent upon external funding from developed country governments rather than being wholly supported financially by the Bank (Tellam 2000). The fact that sustainable energy initiatives are externally driven for the most part, helps to explain why they are poorly integrated within core Bank activities and tend to be "sealed off" from traditional operations (EDF and NRDC 1994). The Bank has, to some extent, acknowledged this weakness in its paper on 'Energy Efficiency and Conservation in the Developing World: The World Bank's Role', where it is recommended that energy efficiency and renewables should be better integrated into the Bank's general country policy dialogue with developing countries (World Bank 1993).

If policy integration is understood in its truest sense, however, the climate impacts of all World Bank policies should be factored into their formulation including policies of energy market deregulation. The Bank concedes 'unregulated electricity markets are likely to put renewable energy technologies at a disadvantage in the short-run because they favour the cheapest energy as determined purely by price, but do not capture environmental and social externalities' (Tellam 2000: 33). In other words, the ecological spillovers from existing policies are not currently internalised. ${ }^{1}$ One report found that less than 10 per cent of all Bank projects are screened for their impact on the climate (SEEN et al. 1997). Between 1995 and 1997 the Bank invested US $\$ 2.24$ billion on the coal sector while over the same period just US\$61 million was spent on demand-side management and only US\$5.9 million on one renewable project (AidWatch 1997). Since 1992, the World Bank has spent 25 times more on climate-changing fossil fuels than on renewables and the fossil fuel projects the World
Bank has financed will over the next 20 to 50 years add carbon dioxide emissions to the atmosphere equivalent to 1.3 times the total amount emitted by all the world's countries in 1995 (SEEN et al. 1997).

To achieve a higher level of policy integration, climate objectives and environmental goals need to be placed on a par with traditional Bank business. This would include goals relating to funding levels of GEF-associated projects and integration into its sector work and the Country Assistance Strategy process, for example. A recent report on the GEF in commenting on the Bank's activities also found that it had not 'taken steps to create staff incentives necessary to put global environmental concerns on a par with traditional bank business; that it is has not systematically integrated global environmental objectives into economic and sector work or into the Country Assistance Strategies (CAS) process and that it has not adequately addressed the impact on the global environment of its financing of fossil fuel power development' (Porter et al. 2001). Clearly, much remains to be done.

The climate-related activities of bilateral aid agencies have also come under increasing scrutiny. As a result, climate change considerations have also been finding their way into traditional ODA programmes such as the German Agency for Technical Cooperation's climate change programme (Measures to Implement the Framework Convention on Climate Change, FCCC). The programme selects developing countries with high levels of greenhouse gas ( $\mathrm{GHG}$ ) emissions such as China and South Africa and targets their energy sectors with projects and programmes aimed at climate change protection. Similarly, the United States Agency for International Development (USAID) has developed a 'Climate Change Initiative' providing grants to address, among other things, policy reform, institutional capacity-building and technology cooperation and transfer. The 'Development Credit Authority' has also been evolved providing guarantees to help project developers overcome market barriers (USAID 1998). Aid, grants and subsidies will continue to be important, particularly to developing countries, for financing climate-relevant technology transfer projects. The financial flows they oversee pale into insignificance, however, when compared with the private sector. 


\section{The role of the private sector}

Given the decline in official development assistance (ODA), much emphasis is placed on the importance of private transfers to developing countries in making up for gaps in public financing. It is difficult to over-state the importance of the private sector in proposals to address climate change. As the Business Council for Sustainable Development acknowledges; 'Industry accounts for more than one third of energy consumed worldwide and uses more energy than any other enduser in industrialised and newly industrialising economies' (Schmidheiny 1992: 43). ${ }^{2}$ The UNFCCC secretariat report on this issue acknowledges the difficulty of analysing the investment pattern of foreign direct investment (FDI) by climate-relevant sectors as its distribution in developing countries is not well documented and the statistics on the transfer of environmentally sound technologies (ESTs) and their impact on GHGs is difficult to determine (UNFCCC Secretariat 1997). Nevertheless, the Asian Development Bank (ADB) found that almost three-quarters of private investment in low-income countries between 1990 and 1997 has gone into constructing new power generation plants using fossil fuels, while the remaining 25 per cent has gone into existing energy utilities. Only a relatively tiny amount of private investment has been made in energy efficiency or renewable energy (ADB Annual Report 1995 cited in Tellam 2000: 184). Besides the use of government incentives to encourage private sector investment in climate benign developments, discussed above, there is a role for screening state support to the private sector and multilateral development banks (MDBs). There is an important potential role for Export Credit Agencies in defining and utilising environmental criteria to control and, if necessary, restrict investments made by MDBs if the political will is there to use this approach. Civil society pressure can help in this regard. In the late 1980s, environmentalists successfully mobilised US Congress to threaten funding for the World Bank unless environmental safeguards were improved (Brown and Fox 2001).

One potentially very powerful critique of this argument, is that what is being suggested here would amount to climate conditionalities that would merely add to the burden of the poorest countries when so many people are without access to energy of any sort. By placing the idea of tackling energy poverty centrally, however, it becomes harder to justify large-scale coal-fired or oil sector projects on the grounds that they help to meet the needs of the poor. Insofar as the plentiful supply of cheap energy is central to sustaining the lives of the urban poor in particular, there may be a case. But, even here, in the context of simultaneous World Bank and IMF pressures to liberalise these sectors, it is clear that the poor are not the reason private companies are willing to take over energy supply in most developing countries and, as a result, are often denied access to improvements in services that may accrue. By far the greatest consumers and beneficiaries of such developments are industry and the rich that can afford to be supplied. Often the energy is transferred overseas. Over 80 per cent of the World Bank Group's support for oil projects in the last decade have been export-oriented oil projects, primarily supplying consumers in North America, Western Europe, Japan and Australia (SEEN 2004).

In rural areas, more sustainable forms of solar or wind energy are often more appropriate for meeting livelihood needs than coal-fired power stations, for example, which are principally designed to meet urban industrial needs but which often externalise short-term human health and environmental costs onto the poor. The same is true for oil. In relation to the Extractive Industries Review commissioned by the World Bank in 2001, the Sustainable Energy and Economy Network claims; 'Over the course of two years of examination, the World Bank Group was unable to provide an example of a single instance where an oil project alleviated poverty. Many examples were provided of oil projects that exacerbated poverty'.

While there may be a case for supporting fossilfuel energy developments in some cases, where alternatives are under-developed or not practically implemented, the sooner the transition to sustainable forms of energy commences, the easier will be the adjustment. There is no doubt, should they be willing, that multilateral development banks and donors could play a key role in enabling that transition. In many ways, their function would be merely to assist those efforts already being made by many developing countries themselves to promote sustainable forms of energy production. India and China have begun to put resources into the development of renewable energy, for example 
and the declaration of the Brasilia Platform on Renewable Energies set a goal for Latin American countries to meet 10 per cent of their total energy consumption from renewables by 2010 .

Taken further, however, a critique of an argument for coherence and policy screening would question why climate change policy objectives should trump other competing development goals, especially when many important uncertainties remain. As the World Bank acknowledges: 'Striking the right balance between vital energy development and protection of the environment is complex in theory and even more challenging in practice' (IFC 2000). The issue is not to construct a new hierarchy of policy priorities however, but to bring about a degree of policy integration such that policies aimed at reducing the threat of climate change are not systematically undermined by the effects of trade, aid and development policy more generally. It is not about diverting money to climate change or creating new climate policies. It is about reviewing existing industrial and other polices that accelerate the climate change which the donor community acknowledges is exacerbating poverty. As the environmental group, Sustainable Energy and Economy Network (SEEN) note, 'Numerous studies have identified the poor as the most vulnerable to climate change. In this sense, the Bank's financing of fossil fuels is putting its own clients at risk' (SEEN 2004 and SEEN 'Talking Points').

\section{A role for adaptation}

The arguments rehearsed above do not negate the significance of adaptation efforts aimed at helping the poorest and most vulnerable to adapt to the reality of climate change that they are already living with. There is a strong case for reducing the impact of climate change on the poor by integrating adaptation responses into development planning as suggested by donors in their Poverty and Climate Change report (Sperling 2003). Decades of inaction now mean that short-term adaptation is imperative. If, however, the efforts of the development community become narrowly preoccupied with this admittedly important contribution, we may be missing an important opportunity to reconsider the role of aid and development policy in promoting forms of development that are destructive of the climate system. Clearly it is not a question of choosing mitigation over adaptation, as donors acknowledge. Both are important. But to leave climate mitigation strategies to environment ministries while development bureaucrats channel all their efforts into adaptation would be a mistake given the pressing need for policy coherence across government.

While donors call for 'steps towards mainstreaming climate issues into all national, subnational and sectoral planning processes such as Poverty Reduction Strategies or national strategies for sustainable development' (Sperling 2003: xi), the focus is on piggy-backing on other institutional processes that build 'the resilience of countries, communities and households to all types of shocks, including climate change impacts'. Integration, according, to the definition used in the report, occurs 'when specific adaptation measures are added to design and implementation strategies' (p. 15). Again, there is nothing wrong in this at all. But the same logic of mainstreaming could be applied, with tremendous effect, if it dealt with the design stage of policies in sectors that cause climate change in the first place.

In an ironic twist, the report expresses concern about the fact that 'The rate and pattern of economic growth is a critical element of poverty eradication and climatic factors can have a powerful bearing on both' (p. xi). It continues, 'Climate change can depress the economy by affecting the sources of growth' (p. 20). Hence, far from a problem driven by conventional patterns of economic growth, its turns out that our primary concern should be the way in which the climate change generated by that model affects prospects for further growth. Donors' priorities are further underscored where it is noted that 'Integration [with existing adaptation efforts] will prevent climate change diverting limited resources into disaster relief and recovery activities and away from long-term development priorities' (p. xi). The statement reveals both that climate change is not a long-term development priority, while also overlooking the role of climate change in causing the very disasters that require recovery activities.

The report does, nevertheless, express a sincere desire on the part of donors to 'take the lead in internalizing climate issues in all their work' even requiring the 'possible modification of their own institutional processes to ensure climate vulnerability is addressed with due diligence' (p. 29). Acknowledging, as the report does, that adaptation efforts are poorly embedded across 
governments because of the concentration of work within Ministries of Environment, which have limited links and leverage over other line ministries, could be the starting point for moves to integrate mitigation efforts across government. My concern is that what is still missing is an acknowledgement of the need for economic and trade agencies to internalise the climate costs generated by their own policies.

\section{Conclusion}

Building coalitions for the sorts of climate change and development agenda I am proposing here will not be easy and will not be achieved any time soon. Donors, NGOs and others willing to embrace this approach will find themselves pitted in opposition against the most powerful elements of government and their allies in industry that are strongly attached to fossil-fuel-led growth trajectories (Newell 2000). Arguing that there is an overwhelming developmental and environmental case for revising many conventional economic strategies may not make much headway with hard-headed officials from trade and finance ministries.

\section{Notes}

* Some of the empirical material in this paper draws from the author's report on financing of climate change for the Swedish government review on financing public goods, Financing and Providing Global Public Goods: Expectations and Prospects, Ministry of Foreign Affairs, 2001.

1. A Swedish NGO report, A Negawatt saved came to the similar conclusion that 'the World Bank's efforts in pursuing integrated energy strategies have been inconsistent ...

\section{References}

AidWatch, 1997, Aiding Global Warming: An Analysis of Official Development Assistance for the Coal Industry, Australia

Brown, D.L. and Fox, J., 2001, 'Transnational Civil Society Coalitions and the World Bank: Lessons from Project and Policy Influence Campaigns', in M. Edwards and J. Gaventa (eds), Global Citizen Action, Boulder: Lynne Rienner Press

EDF and NRDC, 1994, Power Failure: A Review of the World Bank's Implementation of its New Energy Policy, Washington, D.C.

Grant, W., Matthews, D. and Newell, P., 2000, The Effectiveness of EU Environmental Policy, Basingstoke: Macmillan
There is a case that can and is being made, however, on grounds of the enormous savings to be made from "win-win", "no-regrets" policy options that can be achieved in the short term, at little cost and can be justified on many grounds other than the seriousness of tackling climate change as a problem in its own right. Making the case that a truly "joined-up" approach to policy on climate change may mean revising some policies, or dropping others altogether, will take longer and be resisted fiercely. In the first instance, it means recognising the nonsense of one set of policies, allegedly aimed at enhancing welfare, systematically undermining the asset base on which all economic activity depends. Ultimately, it means recognising that if trade, energy, transport and agricultural policy are more substantively oriented to the goal of sustainability, there should be no need for a separate climate policy. This might require us to revisit our faith in a model of economic development that appears to be increasingly at odds with the goal of stabilising the climate system which so directly impacts upon the livelihoods of the poor.

The status quo of supply-side fossil-fuel fired energy development persists' (cited in Tellam 2000: 39).

2. Greenpeace International (1998) have shown in a comparison of $\mathrm{CO}_{2}$ emissions from the burning of fossil fuels by oil majors with country emissions from fossil fuel combustion, that Shell emits more than Saudi Arabia, Amoco more than Canada, Mobil more than Australia and BP, Exxon and Texaco more than France, Spain and the Netherlands.

Greenpeace International, 1998, The Oil Industry and Climate Change: A Greenpeace Briefing, Amsterdam: Greenpeace International

IFC, 2000, Fuel for Thought: An Environmental Strategy for the Energy Sector, Environment Department and Energy, Mining and Telecoms Department, Washington, D.C.: World Bank

Newell, P., 2000, Climate for Change: Non-State Actors and the Global Politics of the Greenhouse, Cambridge: Cambridge University Press

Porter, G., Clémençon, R., Ofosu-Amaah,W. and Phillips, M., 2001, 'Study of GEF's overall performance', Working Paper, Washington, D.C.: GEF 
Schmidheiny, S. and the Business Council for Sustainable Development, 1992, Changing Course, Massachusetts: MIT Press

SEEN (Sustainable Energy and Economy Network), 2004, SEEN Key Facts, February, www.seen.org, accessed February 2004

SEEN (nd), 'Talking Points' on World Bank Group response to NGO submissions to its 'Extractive Industries Review'. Accessed from Can-talk, NGO email list on climate change

SEEN, International Trade Information Service, US, Halifax Initiative, Canada and Reform the World Bank Campaign, 1997, The World Bank and the G7: Changing the Earth's Climate for Business: An Analysis of the World Bank Fossil Fuel Project Lending since the 1992 Earth Summit, June, Italy Sperling, F. (ed.), Multi-Agency Report, 2003, Poverty and Climate Change: Reducing the Vulnerability of the Poor Through Adaptation, Washington, D.C.: World Bank
Tellam, I. (ed.), 2000, Fuel for Change: World Bank Energy Policy - Rhetoric and Reality, London: Zed Books

UNFCCC Secretariat, 1997, 'Trends of financial flows and terms and conditions employed by multilateral lending institutions', First Technical Paper on Terms of Transfer of Technology and Knowhow, 25/7/97, FCCC/TP/1997/1, Geneva: FCCC Secretariat

USAID, 1998, Climate Change Initiative 1998-2002, Washington, D.C.: USAID

World Bank, 1993, Energy Efficiency and Conservation in the Developing World: The World Bank's Role, Washington, D.C.: The World Bank 